\title{
Task switching under predictable and unpredictable circumstances
}

\author{
Nikolaos Andreadis And Philip T. Quinlan \\ University of York, York, England
}

\begin{abstract}
Task switching was examined under predictable and unpredictable circumstances. In the first two experiments (in predictable conditions), the upcoming task was determined by the trial sequence. In unpredictable conditions, this task was signaled by the stimulus. Under speeded conditions, participants had to judge either the parity of a digit or the vowel/consonant nature of a letter. On bivalent trials, a digit and a letter were presented. On univalent trials, a task-relevant character occurred alongside a task-irrelevant character (e.g., "\&"). Task-switching costs were found, and response times were generally slower on bivalent than on univalent trials. This crosstalk effect was reduced when a task repetition was expected. In the final experiment, trial predictability was defined according to whether a task precue was presented prior to or concurrently with the trial stimulus. Contrasting patterns of crosstalk effects were obtained and are discussed in terms of exogenous and endogenous factors that affect task switching.
\end{abstract}

One of the most important and robust effects to emerge from research into task switching is known as the switch cost (Allport, Styles, \& Hsieh, 1994; Gopher, Armony, \& Greenshpan, 2000; Koch, 2003, 2005; Meiran, 1996; Rogers \& Monsell, 1995; Sohn \& Anderson, 2001; Sohn $\&$ Carlson, 2000). Consider a sequential pair of trials in which the first trial is known as trial $n$ and the second trial is known as trial $n+1$. The second of each pair of trials is classified as either a nonswitch trial, where the task is repeated from trial $n$, or a switch trial, where the task on trial $n+1$ is different from that on trial $n$. A switch cost occurs when performance on a switch trial is poorer than it is on a corresponding nonswitch trial.

Predominantly, switch costs have been studied in the context of predictable conditions in which participants are fully informed about which task to engage in on the upcoming trial (see Monsell, 2003, for a recent review). Far less work, however, has examined cases where the requirement to switch is unpredictable in advance of the trial stimulus. This imbalance in the literature is somewhat surprising, given that our everyday activities are punctuated by apparently random events that interrupt the task at hand and demand attention. Given this, the present series of experiments explores task switching under predictable and unpredictable conditions, in a bid to understand better attentional control in dynamically changing environments.

In discussing task-switching performance, a critical concept is the task set. According to Gilbert and Shallice (2002), task set refers to "the set of cognitive operations required to effectively perform the task" (p. 298). Performance in task-switching experiments provides information about the nature of different task sets and how these are managed on a moment-to-moment basis. By one view (see, e.g., Monsell, Yeung, \& Azuma, 2000; Rogers \& Monsell, 1995), switch costs reveal cognitive processes that reflect switching between different task sets-something that has been referred to as task set reconfiguration. The basic idea is that when a person is confronted with a change in task, the operations used for the immediately prior task need to be, in a sense, switched off so that the operations relevant to the new task can be switched on.

Sohn and Anderson (2001) went further and considered the possibility of two components of switch costsnamely, task preparation and task repetition-with the implication being that switch costs may arise for a number of different reasons. One signature of task preparation is that switch costs are reduced because of some form of facilitation on switch trials (an effect that Altmann, 2004, referred to as switch preparation). Such evidence is consistent with the idea that switch costs reflect, in part, the time needed to complete task set reconfiguration (Allport \& Wylie, 2000; Monsell et al., 2000). In contrast, in considering task repetition, Sohn and Anderson claimed that such effects come about because of an "activation boost that makes the repeated task performance more efficient" (p. 764). According to this, part of the switch cost reflects facilitated responding on nonswitch trials because the same operations are repeated from the immediately previous trial. Such ideas stem from the task-set inertia hypothesis as advanced by Allport and colleagues (see, e.g., Allport et al., 1994; Allport \& Wylie, 1999, 2000).

According to this hypothesis, there is persisting activation from a previous task set that takes time to dissipate. In cases where the task is repeated, the persisting activation of

P. T. Quinlan, ptq1@york.ac.uk 
the relevant task set facilitates responding on a nonswitch trial. The task repetition effect arises because of task priming. In a similar vein, Sohn and Carlson (2000) explored the idea that performance on switch trials may also reflect persisting activation of the previous task set. Activation of the task set just executed is primed, but this interferes with the alternative task set that applies on the switch trial. Time-based decay of task set activation plays a central role in such accounts. For instance, with increasing preparation time (i.e., the delay before the next task is presented), it is assumed that the effects of task set interference will diminish (Goschke, 2000; Meiran, Chorev, \& Sapir, 2000).

In attempting to provide a detailed account of taskswitching performance, Sohn and Anderson (2001) discussed switch costs by exploring task preparation and task repetition in terms of a production system model (similar ideas have been explored by Altmann \& Gray, 2008). According to the model, task-relevant facts are stored in declarative memory in so-called information chunks. Each chunk has an associated activation level, and the ease of retrieval of a given chunk depends on its level of activation. Higher levels of activation reflect easier retrieval, and activation levels decay over time. Consequently, it is easier to retrieve a recently activated chunk than a chunk activated less recently, and this readily accounts for the priming benefit that occurs on nonswitch trials.

The production system model also addresses task predictability: When participants can predict the upcoming task, they can circumvent operations that are otherwise needed to identify that task. To account for the task preparation effect under predictable circumstances, it is assumed that the production rules that specify task identification are not accessed.

Sohn and Anderson (2001) tested the model by manipulating both preparation time and task predictability in task-switching experiments. They examined the effects of preparation time by varying the delay- known as the response-stimulus interval (RSI) - between the execution of the response on trial $n$ and the presentation of the stimulus on trial $n+1$. To examine task predictability, they compared performance in what they termed foreknowledge and no-foreknowledge conditions. In both conditions, the stimulus on a trial comprised a pair of characters that contained one letter and one digit. Depending on the color of the stimulus pair, participants had to undertake either a speeded letter-classification task (i.e., classify the letter as either consonant or vowel) or a speeded digit-classification task (i.e., classify the digit as either odd or even). Trials were tested in blocks, and within blocks the trials were configured as sequential pairs. In foreknowledge conditions, and because of instructions, once the stimulus on the first of a pair of trials had been presented, participants knew what the task on the second would be. In contrast, in the no-foreknowledge conditions, the second task remained unknown until the stimulus was presented.

In the context of Sohn and Anderson's (2001) model, certain key predictions were made about how switch costs would be affected by a variation in preparation time. In particular, it was predicted that the size of the switch costs would diminish as a function of increasing RSI but that the reduction would arise for different reasons in the noforeknowledge and foreknowledge conditions. In the noforeknowledge condition, the facilitative nature of task repetition would decrease as RSI increased; this effect would be revealed as slowing on nonswitch trials. In addition, there should be little benefit on switch trials, regardless of RSI, because of lack of foreknowledge of the upcoming task.

In the foreknowledge condition, it was predicted that the reductions in switch costs would occur because of a reduction in the task repetition effect together with an increase in task preparation. Response times (RTs) on switch trials should shorten with the delay, because of increasing preparedness for the task switch. Generally speaking, the data were in line with these predictions.

In summary, the overriding claims were that in the noforeknowledge condition, switch costs reflect only task set inertia (i.e., residual activation of the previous task set), whereas the switch costs in the foreknowledge condition reflect both task set inertia and task set reconfiguration. These ideas provided the initial theoretical motivation for the experiments reported here.

\section{Different Operational Definitions of Task Predictability}

In the experiments run by Sohn and Anderson (2001), the experimental trials were very clearly divided into sequential pairs, with feedback being given after the response to the second trial in each pair. The color of the stimulus cued the task on each trial. In the present experiments, the trials within a block were run in a seamless sequence of events, as is more traditionally the case in RT studies. Under predictable conditions, the ordinal position of a trial in a block defined the task (i.e., as either Task A or Task B). Following Rogers and Monsell (1995), an alternating runs paradigm was used in which the task sequence was AABBAABB. ... In contrast, in the unpredictable conditions, participants did not know which task to engage in prior to the presentation of the trial stimulus. The appropriate task was signaled by some predesignated characteristic of the trial stimulus.

Such procedural details are important when thinking about task predictability because this has been examined in a different way-a procedure known as explicit cuing has been used (see Altmann, 2007, for an extensive review). With explicit cuing, the claim is that the tasks are unpredictable because the order of the tasks is randomized (see Monsell, Sumner, \& Waters, 2003): The nature of the upcoming task is signaled by a precue that is displayed during the RSI. Such experiments have been reported by Tornay and Milán (2001). They examined performance in what they termed predictable and random conditions. In their first experiment, in the predictable condition, the order of the tasks was given by an alternating runs sequence. In the random condition, the order of the tasks was randomized. However, in both conditions, a precue signaled the upcoming task (see also Koch, 2003). Two RSIs were tested, and it was found that as the delay increased from 200 to $1,200 \mathrm{msec}$, switch costs decreased. The striking finding, though, was that there was no switch 
cost in the random condition at the 1,200-msec RSI. Under random conditions, in which the upcoming task was explicitly cued, Tornay and Milán found that participants were able to complete task set reconfiguration prior to a switch trial.

This pattern of results is interesting because it stands in contrast to those reported by Sohn and Anderson (2001). In their data, switch costs were generally larger under predictable than under unpredictable conditions, and costs did decrease as RSI increased. Notably, though, switch costs were present in data for the unpredictable condition at the longest RSI (i.e., 1,500 msec), and this contrasts with the findings reported by Tornay and Milán (2001). However, given the procedural differences across the two studies, the reasons for the contrasting patterns of findings remain unclear. In an attempt to provide some clarification on the matter, we further examined the basic effects in the present experiments.

\section{Endogenous and Exogenous Factors in Task Switching}

In designing the present experiment, we considered issues concerning task preparation central, and a primary motivation was to establish components of task set control that could be distinguished according to endogenous and exogenous factors (Rogers \& Monsell, 1995). Endogenous factors relate to the participant's intentions - for instance, adopting a particular task set prior to the onset of a trial. For Sohn and Anderson (2001), endogenous factors are those that influence task preparation, and these are dealt with well by their model.

In contrast, exogenous factors are those that affect performance only once the stimulus is presented. Sohn and Anderson (2001) did not consider these in any detail, whereas Rogers and Monsell (1995) did. They used the same component tasks as Sohn and Anderson but went further in distinguishing three types of trials. On congruent trials, both characters were mapped to the same response. For instance, if the "odd" and "consonant" responses were mapped to one key and "even" and "vowel" to a different key, then " $3 \mathrm{~K}$ " would be known as a congruent stimulus. On incongruent trials, the different characters were mapped to different responses (e.g., "3A"). Finally, on neutral trials, only one task-relevant character was presented. For example, with " $3 \#$," only " 3 " was mapped to a response. This manipulation of congruency reflects an exogenous factor because task congruency is apparent only once the stimulus has been presented.

Similar manipulations of stimulus congruence occur frequently in the general attentional literature (see, e.g., the work on the Eriksen flanker effect; Eriksen \& Eriksen, 1974), but it is important to distinguish congruency effects from crosstalk effects (Rogers \& Monsell, 1995). In their first experiment, Rogers and Monsell found a basic crosstalk effect such that there was an overall cost in performance on trials where two task-relevant characters were presented relative to when only one task-relevant character was presented. This pattern of findings rests on the difference between bivalent and univalent stimuli (Pashler, 2000). Bivalent stimuli invoke two different task sets (e.g., "3A"), whereas univalent stimuli invoke only a single task set (e.g., "3\#") With bivalent stimuli, and in the absence of additional information, there is uncertainty over which task set is appropriate. This uncertainty is not present with univalent stimuli, and, consequently, there are performance costs associated with bivalent stimuli (see Quinlan \& Dyson, 2008, chap. 9, for a review of such performance differences).

Crosstalk can also be construed as further evidence of task set interference. With bivalent stimuli, both component characters invoke their respective task sets. Consequently, there is competition at the cognitive level over which task set ought to be executed. In contrast, congruency effects are taken to reflect both (1) benefits when the stimulus invokes only one response and (2) costs when competing responses are invoked. When defined in these terms, the implication is that the effects of crosstalk and congruence operate in different ways and reflect different aspects of task switching. Nonetheless, both crosstalk and congruence effects reflect the fact that once the stimulus is presented, exogenous factors influence performance. Both effects are explored in the following experiments.

The present article contains reports of three experiments. The first two focused on performance in the component tasks, as described by Rogers and Monsell (1995), in predictable and unpredictable conditions. The principal aim was to examine both exogenous and endogenous factors in a bid to illuminate the cognitive processes that underlie task switching. Predictions made by Sohn and Anderson (2001) were central, but each of the experiments also allowed us to examine the pattern of performance reported by Tornay and Milán (2001). To what extent can task set reconfiguration be accomplished when the upcoming task is unpredictable? Indeed, in the final experiment, we explored performance in an explicit cuing paradigm very similar to that reported by Tornay and Milán. In the uncued condition, the trial order was randomized, and the task was signaled by the trial stimulus itself. In the cued condition, trials were also randomized, but now, prior to each trial, a precue was presented during the RSI.

\section{EXPERIMENT 1}

Central to the first experiment were two manipulations of endogenous control. The first involved task predictability. Participants were tested under both predictable and unpredictable conditions. The experiment follows closely on from the first experiment reported by Rogers and Monsell (1995). On each trial, a pair of characters was presented in one of four quadrants of a centrally positioned square. If the stimulus fell in either of the upper two quadrants, participants had to classify the letter as a consonant or a vowel, and if the stimulus fell in either of the lower two quadrants, participants had to classify the digit as either odd or even. In the predictable condition and across trials, the stimulus rotated around the quadrants in a clockwise fashion. In the unpredictable condition, the position of the stimulus was, essentially, determined at random.

The second manipulation concerned variation in RSI, and intervals of 250,600 , and $1,200 \mathrm{msec}$ were tested. 
From their model, Sohn and Anderson (2001) predicted that the reduction in switch costs should be more marked in the predictable than in the unpredictable conditions as the RSI increased. However, in neither of their experiments was the critical higher order interaction statistically reliable. The question was, therefore, whether such a pattern would emerge when performance was tested using an alternating runs paradigm (Rogers \& Monsell, 1995), as opposed to a trial pairs paradigm (Sohn \& Anderson, 2001). Aligned to this was the aspiration to see whether switch costs under unpredictable conditions would occur at the longest (i.e., 1,200-msec) RSI (cf. Tornay \& Milán, 2001).

The experiment also provided an opportunity to examine exogenous factors and how congruence and crosstalk would vary as a function of predictability, RSI, and task switching. If these kinds of stimulus effects reflect automatic processes, they should remain relatively stable regardless of the manipulations of predictability and task delay (cf. Rogers \& Monsell, 1995; see also Monsell et al., 2003, p. 338). Any corresponding factorial interactions would undermine such a conclusion.

\section{Method}

Participants. The participants were 36 university students (7 males, 29 females) with a mean age of 20.3 years $(S D=1.9)$. They took part for either course credit or payment (£4). All reported having normal or corrected-to-normal vision and hearing. Six were left-handed.

Design and Stimuli. Central to the experiment were two character classification tasks (cf. Rogers \& Monsell, 1995). On each trial, a pair of characters was presented, and participants had to make a speeded keypress response. In the letter-classification task, participants had to decide whether the letter was a vowel (from the set $A, U, I, E$ ) or a consonant (from the set $M, K, G, R$ ). In the digitclassification task, the participants had to decide whether the digit was an odd number (from the set 3, 5, 7,9) or an even number (from the set 2, 4, 6, 8). The "consonant" and the "even" responses were assigned to the right key, and the "vowel" and "odd" responses to the left key.

Over trials, the task-relevant character occurred in the first or second character position at random. On congruent trials, both characters were assigned to the same key response (e.g., "A3," "K6"). On incongruent trials, the characters were assigned to different key responses (e.g., "U4," "G9"). Neutral trials occurred when the taskrelevant character was presented together with a neutral character. The neutral character was taken from the set "?," "\%o," "**, "\#." Congruent and incongruent stimuli were bivalent stimuli, and neutral stimuli were univalent stimuli.

In the predictable condition, the trial order was given by an alternating runs sequence starting with a letter trial. Each block comprised 48 trials. Within a block, there were equal numbers of switch and nonswitch trials; equal numbers of congruent, incongruent, and neutral trials; equal numbers of letter and digit trials; and equal numbers of designated left (consonant/even) and right (vowel/odd) response trials. A further constraint was that a character that appeared on trial $n$ never appeared on trial $n+1$.

In the unpredictable condition, and from the participant's point of view, the sequence of trials was random, because a given trial type could not have been known in advance of the trial. As far as possible, the same sort of balancing of the different trial types was adhered to in the unpredictable condition as in the predictable condition.

On the experimental trials, the display contained a centrally positioned square divided into four quadrants. The character pair was then presented centrally within one of the quadrants. In the predict- able condition, the position of the character pair rotated round the quadrants in clockwise fashion over trials starting in the top left quadrant. In the unpredictable condition, the assignment of the character pair to a quadrant was determined at random in advance of a trial. In both conditions, if the character pair fell in the upper two quadrants, the letter task was relevant to the trial, and if the character pair fell in the lower two quadrants, the digit task was relevant to the trial.

In configuring the experimental trials, a split-plot design involving four factors was used. RSI $(250,600,1,200 \mathrm{msec})$ constituted a between-groups factor, and stimulus type (congruent, incongruent, neutral), trial transition (switch or nonswitch), and predictability (predictable or unpredictable) were within-participants factors. To keep the testing sessions to a manageable duration, the RSI factor was tested between participants, with participants being randomly assigned to the different RSI groups.

Apparatus. The E-Prime program (Schneider, Eschman, \& Zuccolotto, 2002), running on a Windows XP PC, was used for controlling the experiment. In addition, an E-Prime response box was used to collect the responses. A 15-in. Sony monitor was used throughout (Model CPD-100ES).

Procedure. Participants were tested individually in a small, quiet testing cubicle. The cubicle contained a table, upon which a computer monitor and the response box were placed. Participants sat facing the 15 -in. monitor placed $57 \mathrm{~cm}$ away from a chinrest bolted to the edge of the table.

Prior to the experimental trials, participants underwent training blocks of trials in which only neutral trials were used. Blocks of trials were generated for the separate classification tasks. Each block of trials contained 24 cases, and individual letters and digits were equally represented in each of their blocks (three times each). The training session comprised 16 blocks of trials (i.e., 8 letter blocks and 8 digit blocks). The session began with a letter-classification block, followed by a digit-classification block. The blocks then alternated accordingly.

In the training blocks, at the start of each trial, a central fixation plus sign $\left(0.4^{\circ} \times 0.4^{\circ}\right.$ of visual angle $)$ was presented, followed by a centrally presented pair of characters. Character pairs were presented as black, bold, 18-point Courier New font $\left(0.5^{\circ} \times 0.5^{\circ}\right)$. Depending on the participant's group, the fixation plus sign occurred for 250 600 , or $1,200 \mathrm{msec}$. The character pair remained on for $3 \mathrm{sec}$ or until a response occurred. Immediately following this, the fixation plus sign returned for the corresponding RSI.

In the experimental trials, the fixation plus sign was presented for the relevant RSI and was followed by a display containing a large square $\left(9^{\circ} \times 9^{\circ}\right)$ divided into quadrants $\left(4.5^{\circ} \times 4.5^{\circ}\right)$. The character pair was presented centrally in one of the quadrants. This display remained on for $5 \mathrm{sec}$ or until a response occurred. Immediately following this, the display was removed and replaced by the fixation plus sign for the corresponding RSI. In case of an error, a sound (beep) occurred for $20 \mathrm{msec}$, and an additional delay of $1.5 \mathrm{sec}$ was added to the RSI.

At the end of each block of experimental trials, detailed feedback was given. A screen display provided the average RT, number of correct responses, number of errors, and percentage of errors. Participants were advised to slow down if they were making a lot of mistakes.

Predictable and unpredictable conditions were configured in two different sets. Each set comprised two sequences of four blocks of 48 experimental trials. Each sequence (i.e., A and B) was presented once, and the blocks were balanced across participants such that half the sample was tested according to the sequence ABBA and half with $\mathrm{BAAB}$.

\section{Results}

Error responses, very fast responses (less than $100 \mathrm{msec}$ ), and responses that followed an error were excluded from the analysis of the RT data. As a conse- 
quence, a total of $9.3 \%$ of the scores were removed prior to data analysis. Separate analyses were carried out for mean correct RTs and percentage errors. Error rates were arcsine transformed prior to analysis (see Keppel \& Wickens, 2004). For both RTs and errors, a split-plot ANOVA was carried out in which RSI $(250,600$, and 1,200 msec) acted as a between-participants grouping factor; the withinparticipants factors were predictability (predictable vs. unpredictable), trial transition (switch vs. nonswitch), and stimulus type (congruent, incongruent, neutral).

RTs. The analysis revealed statistically significant main effects of trial transition $\left[F(1,33)=108.53, M S_{\mathrm{e}}=\right.$ $120,812, p<.001]$, stimulus type $[F(2,66)=235.63$, $\left.M S_{\mathrm{e}}=7,399, p<.001\right]$, and predictability $[F(1,33)=$ $\left.175.64, M S_{\mathrm{e}}=31,531, p<.001\right]$. The main effect of RSI failed to reach statistical significance. Indeed, there were no effects of RSI at all. Figure 1 provides a graphical illustration of summary RT data averaged over the RSI factor (mean percentage error rates are also included).

Generally speaking, responses were slower on switch than on nonswitch trials, slower overall on unpredictable than on predictable trials, and slower overall on bivalent trials than on univalent trials; there was clear evidence of crosstalk. These general patterns were, however, modulated by a number of statistically significant interactions - namely, the predictability $\times$ trial transition inter- action $\left[F(2,33)=29.3, M S_{\mathrm{e}}=9,344, p<.001\right]$, the trial transition $\times$ stimulus type interaction $[F(2,66)=21.9$, $\left.M S_{\mathrm{e}}=3,104, p<.001\right]$, and the predictability $\times$ trial transition $\times$ stimulus type interaction $[F(2,66)=6.20$, $\left.M S_{\mathrm{e}}=3,633, p<.01\right]$.

The predictability $\times$ trial transition interaction revealed that the size of the switch cost was statistically larger in the predictable than in the unpredictable condition (398 and $298 \mathrm{msec}$, respectively). This pattern was also reported by Sohn and Anderson (2001). However, this two-way interaction was itself compounded by the higher order predictability $\times$ trial transition $\times$ stimulus type interaction. This shows that the switch costs varied as a function of crosstalk. To examine the switch costs in the absence of crosstalk, we computed the effects (i.e., mean switch trial RT mean repeat trial RT) separately for predictable and unpredictable neutral trials. A paired $t$ test revealed that switch costs on neutral trials were statistically larger on predictable trials (i.e., $322 \mathrm{msec}$ ) than on unpredictable trials (i.e., $277 \mathrm{msec})[t(35)=2.05, p<.05$, two-tailed test $]$.

To examine the predictability $\times$ trial transition $\times$ stimulus type interaction in more detail, we analyzed the data for predictable and unpredictable cases separately.

Predictable trials. The data were now entered into a two-way, repeated measures ANOVA in which trial transition and stimulus type were entered as fixed factors. The

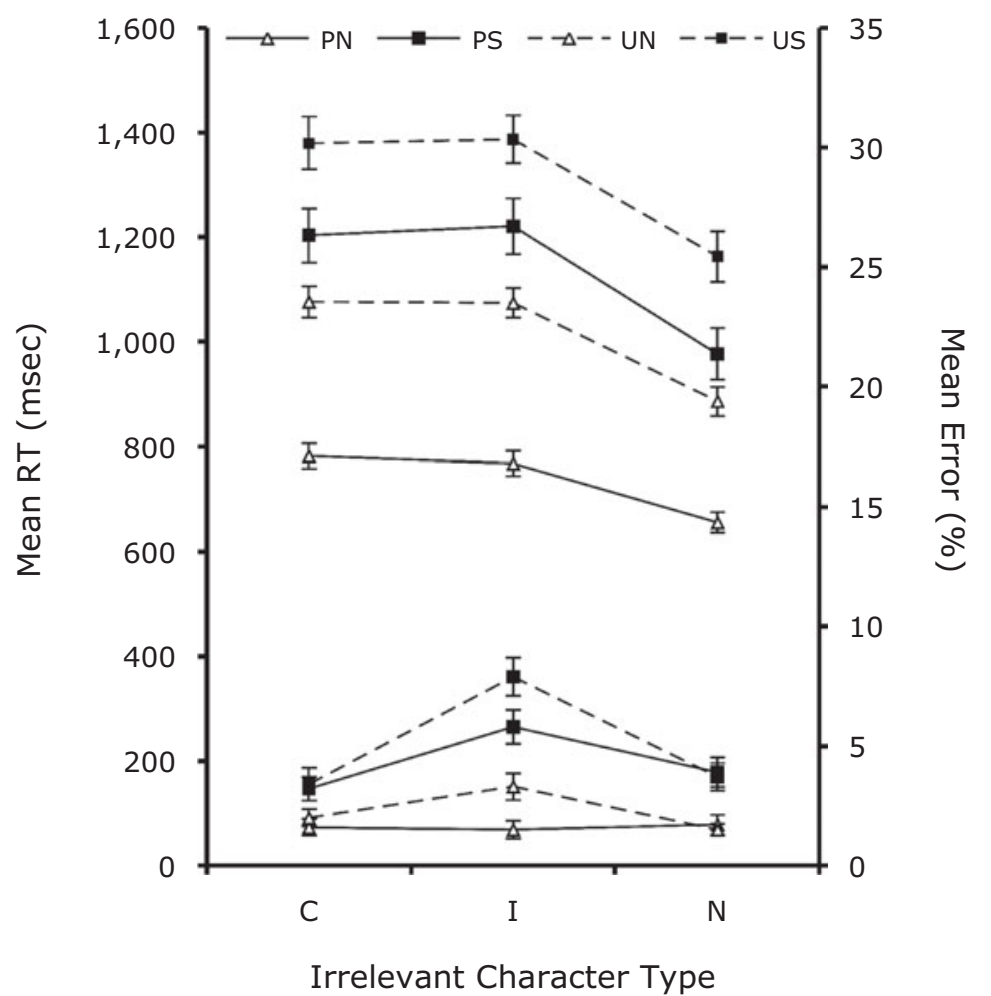

Figure 1. Graphical illustration of the average response times (RTs) and errors for the conditions of interest in Experiment 1. Means have been averaged over response-stimulus intervals. PN, predictable nonswitch trials; PS, predictable switch trials; UN, unpredictable nonswitch trials; US, unpredictable switch trials; $C$, congruent; I, incongruent; N, neutral. Error bars reflect within-participants standard errors after variation between participants was removed (after Bakeman \& McArthur, 1996). 
main effects of both trial transition $[F(1,35)=104.72$, $\left.M S_{\mathrm{e}}=82,007, p<.001\right]$ and stimulus type $[F(2,70)=$ $\left.150.57, M S_{\mathrm{e}}=4,986, p<.001\right]$ were statistically reliable, as was the trial transition $\times$ stimulus type interaction $\left[F(2,70)=25.95 M S_{\mathrm{e}}=3,256, p<.001\right]$. Further examination of the interaction, via a Tukey's HSD test, revealed that the switch costs on congruent and incongruent trials were equivalent $(p>.05)$ and reliably larger than those on neutral trials $(p<.05)$.

Unpredictable trials. For the data from the unpredictable trials, only the main effects of trial transition $\left[F(1,35)=88.76, M S_{\mathrm{e}}=54,052, p<.001\right]$ and stimulus type $\left[F(2,70)=163.19, M S_{\mathrm{e}}=6,138, p<.001\right]$ were statistically significant.

Error rates. Error rates were analyzed in the same way as the RTs. The associated ANOVA revealed that the main effects of trial transition $\left[F(1,33)=73.00, M S_{\mathrm{e}}=.044\right.$, $p<.001]$, stimulus type $\left[F(2,66)=14.35, M S_{\mathrm{e}}=.039\right.$, $p<.001]$, and predictability $\left[F(1,33)=10.37, M S_{\mathrm{e}}=\right.$ $.019, p<.01]$ all reached statistical reliability. In addition, the two-way interactions between predictability and stimulus type $\left[F(2,66)=7.19, M S_{\mathrm{e}}=.02, p<.01\right]$ and between trial transition and stimulus type $[F(2,66)=10.22$, $\left.M S_{\mathrm{e}}=.024, p<.001\right]$ were also found to be statistically significant.

In the case of the predictability $\times$ stimulus type interaction, simple main effects analyses revealed that the stimulus type effect was evident in both the predictable
$\left[F(2,66)=3.58, M S_{\mathrm{e}}=.02, p<.05\right]$ and the unpredictable $\left[F(2,66)=17.38, M S_{\mathrm{e}}=.04, p<.001\right]$ conditions. Visual inspection of the data (see Figure 1), however, revealed that the effect was more marked in the unpredictable than in the predictable condition.

In the case of the trial transition $\times$ stimulus type interaction, the stimulus type effect was statistically significant only in the data for the switch trials $[F(2,66)=22.72$, $\left.M S_{\mathrm{e}}=.03, p<.001\right]$. Participants were particularly prone to make errors on incongruent switch trials. An implication of this result is that it reflects a rather selective speed/ error trade-off such that relatively speeded responses on these trials were offset by relatively more errors. This pattern is present in the data reported by Rogers and Monsell (1995, Figure 2), but, in that case, the effects were not statistically reliable. The general pattern endorses the view, expressed by Rogers and Monsell, that the "competing task-set was not entirely disabled . . . after a task switch" (p. 216).

Interpretation of the accuracy data is also constrained by the following. On congruent trials, both characters were mapped to the same response; hence, responses based on the irrelevant character would have produced "correct" responses even though they were actually errors. The relatively low incidence of errors on congruent trials is in line with this possibility.

Further analyses of the crosstalk effects. The results apparently indicate that the crosstalk effects were reduced

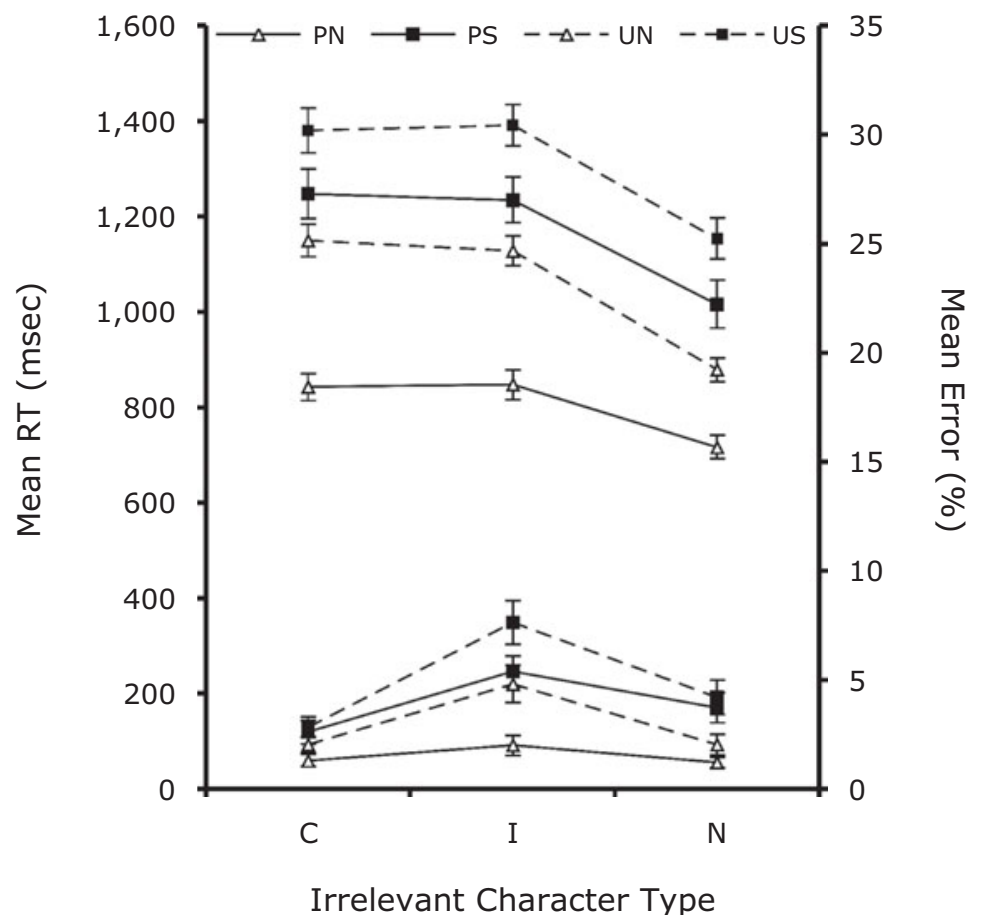

Figure 2. Graphical illustration of the response times (RTs) for the conditions of interest in Experiment 2. Means have been averaged over response-stimulus intervals. PN, predictable nonswitch trials; PS, predictable switch trials; UN, unpredictable nonswitch trials; US, unpredictable switch trials; C, congruent; I, incongruent; $N$, neutral. Error bars reflect within-participants standard errors after variation between participants was removed (after Bakeman \& McArthur, 1996). 
in the predictable nonswitch condition, and to examine this, we carried out the following additional analysis on the RT data. First, an index of crosstalk in each of the predictable and unpredictable nonswitch and switch cases was computed. The average of the mean RTs on the bivalent (congruent and incongruent) trials was calculated, and the mean RT on univalent (neutral) trials was subtracted from this average to give a difference score. Difference scores were computed on a participant-by-participant basis for each of the four conditions. These difference scores were then entered into a split-plot ANOVA in which the same RSI, predictability, and trial transition factors were used as before. This analysis revealed that the main effect of trial transition $\left[F(1,33)=36.64, M S_{\mathrm{e}}=5,258, p<\right.$ $.001]$ was statistically significant. The predictability effect $\left[F(1,33)=3.931, M S_{\mathrm{e}}=6,891, p=.056\right]$ just failed to reach statistical reliability. Finally, the predictability $x$ trial transition interaction was also statistically significant $\left[F(3,99)=11.18, M S_{\mathrm{e}}=5,739, p<.01\right]$.

Further examination of the predictability $\times$ trial transition interaction was undertaken using a Tukey's HSD test. This revealed that the smallest amount of crosstalk was present in the data for the predictable nonswitch trials (119 msec; $p<.05$, all comparisons). No other pairwise comparisons reached statistical significance $(p>.05)$. The crosstalk effects were 189, 220, and $235 \mathrm{msec}$ for the unpredictable nonswitch, unpredictable switch, and predictable switch cases, respectively.

\section{Discussion}

In the predictable condition, the present data reveal all of the basic effects reported by Rogers and Monsell (1995; see their Figure 2, p. 215). Evidence of task crosstalk was clear. RTs were longer on bivalent trials than they were on univalent trials. Participants were also slower to respond following a task switch than when the task was repeated. The size of the switch costs varied across the different stimulus types. Switch costs were larger on bivalent trials than they were on univalent trials. Effects of congruency were revealed in the accuracy data: Participants were particularly prone to make errors on incongruent switch trials. In addition, and replicating Rogers and Monsell's (1995, Experiment 1) results, there were no statistically reliable effects of RSI.

When performance in the unpredictable conditions was taken into account, the predicted interaction between task predictability, RSI, and task switching discussed by Sohn and Anderson (2001) was not found. A more detailed exploration of issues concerning the RSI factor is included in the Discussion of Experiment 2. However, it is important to note that the experiment failed to replicate the findings, reported by Tornay and Milán (2001), showing that switch costs were abolished at the longest RSI in their unpredictable condition. They explained their data in terms of two forms of task set reconfiguration (after Rogers \& Monsell, 1995) - namely, an exogenous component, triggered by the task stimulus on predictable switch trials, and an endogenous component that operates in random conditions. They claimed that in random conditions, the endogenous component overrides the exogenous com- ponent, and hence, the costs associated with exogenous task reconfiguration are circumvented. Such ideas are of some interest, but they are not in themselves sufficient to explain the present data. We need to consider alternative possibilities because the most interesting effects here are due to crosstalk and not switch costs.

For the predictable condition, the switch costs varied as a function of stimulus type: Switch costs were equivalent and large on the bivalent trials but were significantly less on univalent trials. For the unpredictable condition, the switch costs were the same for bivalent and univalent stimuli. This contrasting pattern of performance is attributable to different patterns of crosstalk in the predictable and unpredictable conditions. Crosstalk effects were reduced in predictable nonswitch circumstances. When participants knew that the same task was to be repeated, crosstalk was reduced relative to cases where (1) they had to switch tasks or (2) they did not know which task to perform. This effect is quite different from both switch preparation, where reduced switch costs arise because of speeding on switch trials, and task repetition, where responses are facilitated on nonswitch trials. Given the unexpected nature of these particular findings, detailed discussion of the crosstalk effects is deferred until all of the experiments have been described.

It is useful to consider how the data accord with the arguments set out by Sohn and Anderson (2001) in other respects. According to Sohn and Anderson, performance in predictable conditions reflects both task set inertia and task set reconfiguration. The facilitated responding on predictable nonswitch trials is consistent with ideas about task set inertia, but the evidence for task set reconfiguration is not as clear-cut. The data show that the longest RTs occurred on unpredictable switch trials, but switch costs were larger on predictable than on unpredictable trials. Interpretation of this contrast is complicated by the task priming effects on predictable nonswitch trials. Nonetheless, there was some benefit on switch trials when the upcoming task was predicted, relative to when it was not. This evidence is consistent with the idea of an endogenous anticipatory component that completes some, but not all, processes associated with task set reconfiguration (see, e.g., DeJong, 2000; Gopher et al., 2000; Goschke, 2000; Meiran, 1996; Rogers \& Monsell, 1995; Sohn \& Carlson, 2000; Tornay \& Milán, 2001). Indeed, overall performance in the predictable condition suggests that participants were intentionally trying to activate and suppress the different task sets according to the trial sequence (cf. Rogers \& Monsell, 1995). The robust switch costs in the predictable condition are taken to reflect the operation of the exogenous component that is triggered by the trial stimulus (see Rogers \& Monsell, 1995).

In considering the data for the unpredictable conditions, it seems that participants attempted to keep active both task sets throughout the blocks of trials. Crosstalk was relatively large, and switch costs were correspondingly small. Both effects suggest that the currently irrelevant task set was not completely deactivated in the unpredictable condition. In this regard, the data are not wholly in accordance with the theoretical account of Sohn and An- 
derson (2001). According to them, performance in unpredictable conditions is mainly indicative of task set inertia. Performance on trial $n+1$ is primarily a function of the passive decay of activation of the task set from trial $n$. In contrast, we suggest that performance in the unpredictable conditions is more in line with the active maintenance of both task sets in working memory over trials. The claim is that participants attempt to prepare themselves to enact either task on any trial in the unpredictable condition.

Having considered how switch costs reflect the influence of both endogenous and exogenous factors, it seems also that both factors influence task crosstalk. Crosstalk reflects task set interference on bivalent trials because each of the task-relevant characters invokes its corresponding task set. What is interesting is that such crosstalk was modulated by the participant's expectations about the upcoming task. Crosstalk was minimal when a nonswitch trial was predicted. In this regard, the data accord well with Koch's (2005) conclusion that "predictability-based task preparation benefits are not switch specific" (p. 111). The reduction of task crosstalk occurred on nonswitch, not switch, trials. Nonetheless, the very particular and unexpected nature of these findings demanded some further consideration. As a consequence, Experiment 2 was designed in a bid to generalize the findings to related but different conditions.

\section{EXPERIMENT 2}

In the next experiment, the character pair was always presented at the center of the screen, and the color of the characters signaled the task to be enacted. Both changes bring the paradigm more in line with the work of Sohn and Anderson (2001), and so further comparisons with their findings are possible.

The changes were also deemed necessary in order to rule out a confound that existed between the predictable and unpredictable conditions in Experiment 1. In the predictable conditions, participants were fully aware of where to look in advance of the next trial, but this was not so in the unpredictable conditions. The differences in performance across the two conditions could, therefore, in part reflect the costs of having to first locate the stimulus once it was presented in the unpredictable condition. It thus seemed important to examine the basic effects uncontaminated by any concomitant differences in eye movements.

\section{Method}

Participants. Participants were 36 university students (6 males, 30 females) with a mean age of 20.7 years $(S D=3.1)$ who took part in this experiment for either course credit or payment. They all reported having normal or corrected-to-normal vision and hearing. Seven were left-handed.

Design and Stimuli. Almost every aspect of the design of Experiment 2 was exactly the same as in Experiment 1 . The significant differences concern the manner in which the stimuli were presented and the means by which the tasks were cued. Now, on each trial, the character pair was presented centrally on the screen (the previous square frame was not used), and participants were instructed to classify the digit when the character pair was presented in green and to classify the letter when the character pair was in red. As in Ex- periment 1 , in the predictable condition, alternating runs sequences were used. In contrast, in the unpredictable condition, and from the participant's point of view, the trial type changed in a random fashion across trials. Again, the color of trial stimulus signaled the task to be carried out.

\section{Results}

Data analysis was the same as in Experiment 1. As before, the data were screened prior to analysis, and a total of $9.2 \%$ of scores were excluded. Figure 2 provides a graphical summary of the RT and error data.

RTs. Statistically significant main effects of trial transition $\left[F(1,33)=121.05, M S_{\mathrm{e}}=85,829, p<.001\right]$, stimulus type $\left[F(2,66)=213.54, M S_{\mathrm{e}}=10,046, p<.001\right]$, and predictability $\left[F(1,33)=100.85, M S_{\mathrm{e}}=41,180, p<\right.$ $.001]$ were found. In addition, the predictability $\times$ trial transition interaction $\left[F(2,33)=14.90, M S_{\mathrm{e}}=21,117\right.$, $p<.01]$, the trial transition $\times$ stimulus type interaction $\left[F(2,66)=3.68, M S_{\mathrm{e}}=3,900, p<.05\right]$, and the predictability $\times$ stimulus type interaction $[F(2,66)=$ $\left.11.29, M S_{\mathrm{e}}=5,066, p<.001\right]$ were found to be statistically significant. The predictability $\times$ trial transition $\times$ stimulus type interaction also reached statistical reliability $\left[F(2,66)=15.66, M S_{\mathrm{e}}=3,338, p<.001\right]$.

As in Experiment 1, the predictability $\times$ trial transition interaction revealed that the switch cost was statistically larger in the predictable than in the unpredictable condition (364 and $256 \mathrm{msec}$, respectively). Again, the data on neutral trials were considered separately in a bid to examine the switch costs in the absence of crosstalk. Although the size of the switch costs was numerically larger on predictable than on unpredictable trials (i.e., 299 and $275 \mathrm{msec}$, respectively), this difference did not reach statistical reliability $[t(35)<1]$.

To examine the predictability $\times$ trial transition $\times$ stimulus type interaction in more detail, the data for predictable and unpredictable cases were analyzed separately.

Predictable trials. The main effects of both trial transition $\left[F(1,35)=96.05, M S_{\mathrm{e}}=74,545, p<.001\right]$ and stimulus type $\left[F(2,70)=140.76, M S_{\mathrm{e}}=5,341, p<.001\right]$ were statistically reliable, as was the trial transition $\times$ stimulus type interaction $\left[F(2,70)=16.28, M S_{\mathrm{e}}=3,517\right.$, $p<.001]$. To understand the nature of this interaction further, an ensuing HSD test showed that, as in Experiment 1, the resulting switch costs were equivalent on the congruent and incongruent trials $(p>.05)$ but larger than the costs on neutral trials (both tests, $p<.05$ ).

Unpredictable trials. On unpredictable trials, only the main effects of trial transition $\left[F(1,35)=85.19, M S_{\mathrm{e}}=\right.$ $41,602, p<.001]$ and stimulus type $[F(2,70)=142.22$, $\left.M S_{\mathrm{e}}=10,199, p<.001\right]$ were statistically significant. As in the previous experiment, the switch costs were additive with stimulus type.

Error rates. The main effects of trial transition $\left[F(1,33)=29.71, M S_{\mathrm{e}}=.059, p<.01\right]$, congruency $\left[F(2,66)=22.96, M S_{\mathrm{e}}=.04, p<.001\right]$, and predictability $\left[F(1,33)=9.82, M S_{\mathrm{e}}=.061, p<.001\right]$ were all statistically reliable. Only the trial transition $\times$ stimulus type interaction $\left[F(2,66)=5.56, M S_{\mathrm{e}}=.028, p<.01\right]$ was found to be statistically significant. To examine this interaction in 
more detail, we carried out simple main effects analyses. These revealed statistically significant crosstalk in the data for both the nonswitch trials $\left[F(2,66)=6.16, M S_{\mathrm{e}}=.04\right.$, $p<.01]$ and the switch trials $\left[F(2,66)=28.32, M S_{\mathrm{e}}=\right.$ $.03, p<.001]$. Nonetheless, the interaction reflected the relatively high number of errors committed on incongruent switch trials. The same effect was present in the data in Experiment 1 and provides further evidence of the difficulties in attempting to suppress the competing task set following a task switch (cf. Rogers \& Monsell, 1995). Aside from this, there are no other signs of any systematic speed/ accuracy trade-offs in the data.

Further analyses of the crosstalk effects. Crosstalk effects were estimated by computing the difference scores in the same manner as in Experiment 1. An analysis of the difference scores revealed that the main effects of both trial transition $\left[F(1,33)=6.79, M S_{\mathrm{e}}=6,150, p<.05\right]$ and predictability $\left[F(1,33)=19.02, M S_{\mathrm{e}}=8,969, p<\right.$ $.001]$ were statistically reliable. In addition, the predictability $\times$ trial transition interaction was statistically significant $\left[F(3,99)=36.04, M S_{\mathrm{e}}=3,883, p<.001\right]$.

Further examination of the predictability $\times$ trial transition interaction was undertaken using a Tukey's HSD test. This revealed that the smallest crosstalk effect was present in the data for the predictable nonswitch trials $(129 \mathrm{msec}$; $p<.05$, all comparisons). The crosstalk effects were 260 , 232 , and $225 \mathrm{msec}$ for the unpredictable nonswitch, unpredictable switch, and predictable switch cases, respectively. No other pairwise comparisons reached statistical significance. This pattern is identical to that reported in Experiment 1.

\section{Discussion}

Perhaps the most salient aspect of the results is the very high degree of concordance with those reported in Experiment 1 . The same patterns of predictability effects and crosstalk effects were found as in Experiment 1. Importantly, the three-way interaction between predictability, trial transition, and stimulus type was reinstated. As before, switching costs were additive, with variation in stimulus type in the data for the unpredictable condition. In contrast, switching costs varied as a function of stimulus type in the data from the predictable condition. The variation in switch costs is, again, attributable to different patterns of crosstalk in the predictable and unpredictable conditions. The basic result was that when a task repetition was predictable, participants found it relatively easy to suppress interference from the irrelevant task set on bivalent stimulus trials. This pattern of performance is explored more thoroughly in the General Discussion.

The close correspondence across the findings of Experiments 1 and 2 also suggests that the possible confounding of eye movements in Experiment 1 across the unpredictable and predictable conditions was not a critical factor. When eye movements were controlled for in Experiment 2, the same general patterns of performance found in Experiment 1 were replicated. The data therefore do reveal the importance of endogenous factors in task switching that are quite independent of operations concerning eye movement control.
In neither Experiment 1 nor Experiment 2 were there robust effects of RSI; hence, the interaction between task predictability, RSI, and task switching discussed by Sohn and Anderson (2001) was not found here. This interaction also was not present in their data, and no corresponding effects of RSI were reported by Rogers and Monsell (1995) either. As with any null effect, interpretation is difficult, but the fact that RSI was blocked across participants may have been the critical factor. It seems, therefore, that Altmann (2004) was correct in stating that RSI effects are most likely to occur when participants experience a range of delays within the same testing conditions. As Altmann (2004) argued, any switch preparation processes that may be engaged during the RSI are given a very low priority when participants experience only one delay duration. Such a claim is consistent with the idea that switch preparation is primarily driven by endogenous factors. To explore this in more detail would demand a different line of investigation, and, on these grounds, further manipulation of RSI was not undertaken in the final experiment. ${ }^{1}$

The lack of RSI effects does underscore a contrast with the data reported by Tornay and Milán (2001). Unfortunately, though, the contrast is due to the lack of a statistically significant interaction between RSI and task transition in the present data. Reasonable concerns may then be raised about this null result. On these grounds, a more powerful test was undertaken in the final experiment, as the sample of participants tested at the longest RSI used in Experiments 1 and 2 was increased from 12 to 36. Performance was assessed again under predictable and unpredictable conditions, and the RSI was set at $1,200 \mathrm{msec}$.

\section{EXPERIMENT 3}

So far, the experiments have been primarily focused on the interplay of task predictability (as an indicator of endogenous processes) and crosstalk (as an indicator of exogenous processes). In Experiments 1 and 2, task predictability was defined in terms of trial order as given by the alternating runs sequences. However, a different way of examining this is by way of the explicit task-cuing paradigm (Altmann, 2007).

In the explicit task-cuing paradigm-even in cases where the trial sequence is random-once the cue is presented, the next task is known with certainty. It seems possible, therefore, that the presentation of the task cue materially affects performance in ways different from what happens when participants operate in strictly unpredictable conditions. Indeed, given that participants may be able to engage in some form of task preparation on the basis of an explicit task precue (Karayanidis et al., 2009; Koch, 2003, 2005; Meiran, 1996), it seemed important to examine such effects with the present tasks.

To pursue such ideas, we may ask whether explicit cuing affects crosstalk in a fashion similar to that found under the predictable conditions in Experiments 1 and 2. We have shown that crosstalk is reduced considerably when participants can predict a task repetition on the basis of the task order. It is of some interest to see whether a similar 
effect obtains when the upcoming task is signaled by a task precue, and not trial order.

In exploring this in the final experiment, we examined performance in two different random conditions. In both conditions, the color of the trial stimulus indicated the task to be performed. The uncued condition was a simple replication of the unpredictable condition in Experiment 2. In contrast, in the cued condition, the fixation cross acted as a task precue, because its color indicated the upcoming task. The primary aim was to examine the sorts of preparatory processes that are invoked by the explicit cue. We predicted that there should be some evidence of task preparation in the cued condition even though the trial order was randomized.

A single RSI of 1,200 msec was used in both conditions. This RSI was chosen because Tornay and Milán (2001) found the most salient differences in performance between their predictable and random cases at this RSI. The cued condition is, essentially, a replication of the random condition tested by Tornay and Milán.

\section{Method}

Participants. Participants were 36 university students (4 males, 32 females) with a mean age of 20.2 years $(S D=2.4)$. They took part for either course credit or payment. All reported having normal or corrected-to-normal vision and hearing, and only 1 was lefthanded.

Design and Stimuli. The basic design of the experiment followed closely that used in Experiment 2, and the uncued condition was simply a replication of the unpredictable condition tested in Experiment 2. In the cued condition, the fixation plus sign acted as a task precue. The plus sign was presented during the 1,200-msec RSI in the color associated with the upcoming task. In the uncued condition, the fixation plus sign was always black.

\section{Results}

Following data screening, a total of $14.2 \%$ of the scores were eliminated prior to data analysis. Figure 3 provides a graphical illustration of both the mean RT and error data.

RTs. In the analysis, the trial transition and stimulus type factors were the same as before; however, the predictability factor was replaced by a cuing factor (cued vs. uncued). The main effects of cuing $\left[F(1,35)=74.62, M S_{\mathrm{e}}=\right.$ $68,831, p<.001]$, trial transition $[F(1,35)=101.84$, $\left.M S_{\mathrm{e}}=40,927, p<.001\right]$, and stimulus type $[F(2,70)=$ $\left.109.21, M S_{\mathrm{e}}=24,052, p<.001\right]$ were all statistically reliable. Moreover, the cuing $\times$ trial transition interaction $\left[F(1,35)=10.83, M S_{\mathrm{e}}=9,429, p<.01\right]$, the cuing $\times$ stimulus type interaction $\left[F(2,70)=14.04, M S_{\mathrm{e}}=6,407\right.$, $p<.001]$, and the trial transition $\times$ stimulus type interaction $\left[F(2,70)=3.64, M S_{\mathrm{e}}=6,312, p<.05\right]$ were also found to be statistically significant. Notably, the cuing $\times$ trial transition $\times$ stimulus type interaction failed to reach statistical significance $\left[F(2,70)=2.80, M S_{\mathrm{e}}=6,871\right.$, $p>.05]$.

The cuing $\times$ trial transition interaction revealed that the switch costs were, on average, larger in the uncued condition than in the cued condition. In a bid to analyze

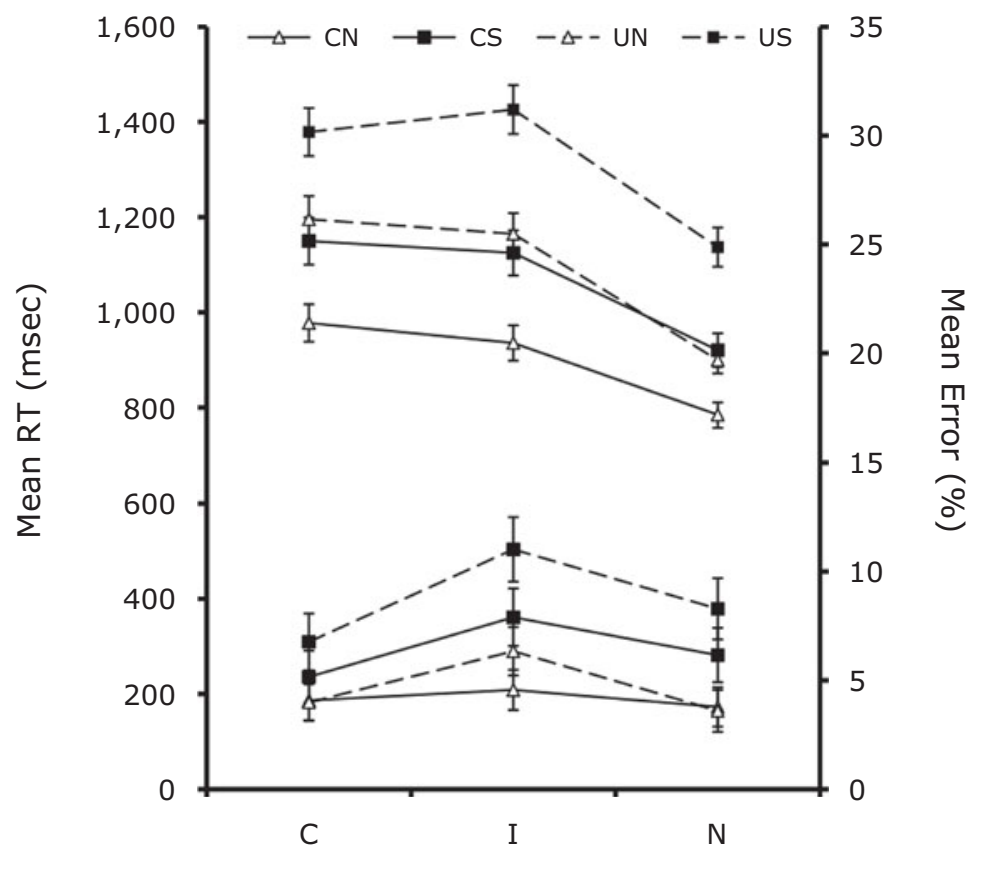

Irrelevant Character Type

Figure 3. Graphical illustration of the response times (RTs) for the conditions of interest in Experiment 3. CN, cued nonswitch trials; CS, cued switch trials; UN, uncued nonswitch trials; US, uncued switch trials; C, congruent; I, incongruent; N, neutral. Error bars reflect within-participants standard errors after variation between participants was removed (after Bakeman \& McArthur, 1996). 
switch costs in the absence of crosstalk, only the data from neutral trials were considered further. As before, on a participant-by-participant basis, switch costs were computed for the neutral trials separately from the cued and uncued conditions. These costs were then analyzed with a paired $t$ test. The results showed that the switch costs were statistically larger in the uncued condition $(237 \mathrm{msec})$ than in the cued condition $(136 \mathrm{msec})[t(35)=3.64, p=$ .001 , two-tailed test].

To examine the cuing $\times$ stimulus type interaction in more detail, we computed crosstalk effects as before for each participant, for the cued and uncued conditions separately. These difference scores were then entered into a paired $t$ test. The test revealed that the size of crosstalk in the cued condition was statistically smaller (194 msec) than that in the uncued condition $(273 \mathrm{msec})[t(35)=$ $5.25, p<.001$, two-tailed test].

Finally, the trial transition $\times$ stimulus type interaction was decomposed using an HSD test. The only pairwise difference to reach statistical significance was that between the means of the congruent and incongruent stimuli $(p<.05)$. The overall averaged switch costs were 178, 225 , and $186 \mathrm{msec}$ in the data for the congruent, incongruent, and neutral trials, respectively. Further inspection of the data revealed that the interaction arose because of relatively short RTs on incongruent nonswitch trials rather than corresponding long RTs on incongruent switch trials. We saw no obvious reason for this particular pattern of responding.

Further analyses of the crosstalk effects. The overall pattern of responding in the present case with precues is apparently different from that found when participants were cued by trial order, as in Experiments 1 and 2. In the previous experiments, the data from the predictable conditions revealed that the level of crosstalk was considerably reduced on the nonswitch relative to the switch trials. To check whether a similar pattern recurred here, the data from the cued trials were examined further in a two-way repeated measures ANOVA in which trial transition and stimulus type were entered as fixed factors. The main effects of both trial transition $\left[F(1,35)=53.87, M S_{\mathrm{e}}=\right.$ $275,522, p<.001]$ and stimulus type $[F(2,70)=78.80$, $\left.M S_{\mathrm{e}}=11,756, p<.001\right]$ were statistically reliable. The trial transition $\times$ stimulus type interaction, however, was not statistically reliable $\left[F(2,70)=2.68, M S_{\mathrm{e}}=5,058\right.$, $p>.05]$. The corresponding interaction in the data for the predictable trials in Experiments 1 and 2 is, in contrast, statistically significant.

However, in a more direct test, the data from all three experiments were examined in the following way. Crosstalk effects were computed for the data from the nonswitch predictable trials in Experiments 1 and 2 and also for the cued nonswitch trials in Experiment 3. The data from Experiments 1 and 2 were combined into a single sample and compared with the separate sample of scores taken from Experiment 3 in an independent samples $t$ test (assuming unequal variances). This test revealed that the size of the crosstalk effect was significantly greater on cued nonswitch trials than it was on predictable nonswitch trials $[t(46.94)=2.28, p<.05$, two-tailed test $]$ (mean RTs were 172 and 124 msec, respectively). Crosstalk was therefore more pronounced on nonswitch trials when participants were provided with trial precues than when the next task was given by trial order.

Error rates. Analysis of the error data revealed that the main effects of cuing $\left[F(1,35)=13.25, M S_{\mathrm{e}}=.034\right.$, $p<.01]$, trial transition $\left[F(1,35)=35.415, M S_{\mathrm{e}}=.06\right.$, $p<.001]$, and stimulus type $\left[F(2,70)=14.91, M S_{\mathrm{e}}=\right.$ $.042, p<.001]$ were all statistically reliable. Participants generally (1) were more accurate in the cued than in the uncued cases, (2) were more inaccurate on switch than on nonswitch trials, and (3) tended to make more errors on incongruent than on congruent or neutral trials.

In addition to these main effects, the cuing $\times$ trial transition interaction $\left[F(1,35)=4.99, M S_{\mathrm{e}}=.035, p<.05\right]$ was statistically reliable. More errors were committed on switch trials in the uncued condition than in all other cases. Generally speaking, the data, as a whole, do not reveal any systematic speed/error trade-offs.

\section{Discussion}

The data clearly reveal important differences in performance that relate to whether or not the upcoming task is precued during the RSI. Both crosstalk and task-switching costs were smaller in the cued than in the uncued condition. In addition, there was no evidence that crosstalk was specifically reduced on nonswitch trials in the cued condition. In this respect, performance was not the same in the cued condition as in the predictable conditions examined in Experiments 1 and 2. These contrasting patterns of performance are explored more thoroughly in the General Discussion.

A particularly notable finding is the evidence of switch preparation in the cued condition. Switch costs were significantly smaller in the cued than in the uncued condition. This clearly shows that some form of advance reconfiguration can take place in so-called random conditions because of the presentation of a task precue (cf. Tornay \& Milán, 2001). In this regard, there is a sense in which the precue renders the task "predictable." Nonetheless, this form of task predictability has quite different consequences for performance than does task predictability based on trial order.

The evidence for switch preparation in the first two experiments is that overall performance on predictable switch trials was better than that on unpredictable trials. In Experiment 3, this pattern was replicated, but switch costs were also significantly smaller in the cued than in the uncued conditions. In the first two experiments, this reduction in switch costs was not apparent in the data for the predictable conditions. Considering the overall patterns of performance, the present data do endorse Koch's (2003) conclusion that "internal cues, in comparison with external cues, result in a much weaker preparation benefit" and that "internally generated cues based on task sequence are comparably ineffective relative to external cues" (p. 491). Such sentiments are returned to in the General Discussion. 
The presence of switch costs at the relatively long RSI of $1,200 \mathrm{msec}$ in the cued condition contrasts with the failure to find switch costs reported by Tornay and Milán (2001) in their random condition. Aside from different kinds of precue used in the two studies (color of the fixation plus sign here, shape of the fixation in their study), the cued condition was a very close replication of their random condition. In fact, in none of the experiments reported here have the effects reported by Tornay and Milán been found, and these are not the only failures to replicate their findings. Monsell et al. (2003) reported a decrease in switch costs with an increase in RSI from 50 to $1,250 \mathrm{msec}$ in both predictable and unpredictable conditions. Moreover, the switch costs remained substantial at the longest RSI. In addition, Sohn and Carlson (2000), in using a paradigm similar to that used by Sohn and Anderson (2001), found reliable switch costs in both foreknowledge and no-foreknowledge conditions when the RSI was $1,000 \mathrm{msec}$. The contrasting pattern of findings regarding switch costs under unpredictable conditions at long RSIs is something that could form the basis of future research. This issue cannot be resolved on the basis of the present experiments.

\section{GENERAL DISCUSSION}

Across three experiments, we examined several endogenous and exogenous factors that determine performance in simple task-switching paradigms. The influence of such factors has been explored in terms of task repetition effects, task-switching effects, and task crosstalk. The most surprising findings concern task crosstalk. It has been accepted that crosstalk occurs because any task-relevant character automatically invokes its associated task set (see Monsell et al., 2000). Response slowing on bivalent relative to univalent trials then directly reflects the sort of task set interference discussed by Rogers and Monsell (1995): On bivalent trials, both task sets are activated, whereas on univalent trials, only one is. However, in the first two experiments, it was established that there was minimal crosstalk when a task repetition was predicted. Under these conditions, it seems that the relevant task set was prioritized, and, therefore, interference from the alternative task set was minimized. This pattern could not have been readily predicted from any of the theoretical accounts of task switching considered at the outset. In considering why this effect may have arisen, the theoretical framework set out by Meiran (2000a, 2000b, 2005) provides some useful pointers.

Meiran (2000a, 2000b) discussed something known as an S-Set. "S-Set" is shorthand for stimulus task set, and this kind of task set controls the representation that codes evidence in terms of the task-relevant dimensions of the stimulus. In the present context, such a representation would capture weighted evidence defined in terms of the vector (odd, even, vowel, consonant). For instance, the stimulus "A3" could be represented as $(1,0,1,0)$, where the component weights vary from 0 to 1 . The values of the weights index the amount of bias that is attributed to the component stimulus dimensions. Meiran (2005) referred to such biasing as "dimensional attentional selection" (p. 1027). The dimensional weights are taken into account during the process of deciding which is the appropriate response on a trial.

This general framework provides some insights into how task predictability modulated the crosstalk effects in Experiments 1 and 2. When participants expected a nonswitch trial, attention was biased to the stimulus dimensions associated with the immediately prior task. Consider the case where the letter task was relevant on trial $n$. On the assumption that a nonswitch trial was expected on trial $n+1$, then the weights associated with "consonant" and "vowel" would be biased (see Meiran, 2005). Consequently, when the stimulus on the nonswitch trial is presented, the generation of the corresponding S-set reflects the biases in the weights associated with the dimensions relevant to the immediately prior task. Activation of the relevant task set is therefore much greater than activation of the irrelevant task set, and task set interference on trial $n+1$ is reduced accordingly. By this account, the reduction of crosstalk is attributable to a biasing of attention toward the task-relevant dimensions of the trial stimulus both before and during stimulus encoding.

Performance in the unpredictable conditions reveals a quite different pattern. Rather than simply waiting until the task type was signaled by the trial stimulus (cf. Sohn \& Carlson, 2000), it seems that participants attempted to keep both task sets active when the next task was uncertain. The evidence taken to support this is that (1) equivalent levels of crosstalk were found on switch and nonswitch trials and (2) switch costs tended to be less on unpredictable than on predictable trials.

The data are also instructive in that it seems that participants were not able to complete task set reconfiguration in advance of a predictable switch trial. The findings accord with the notion of an endogenous anticipatory component that invokes some but not all operations associated with task set reconfiguration (Rogers \& Monsell, 1995). Residual switch costs have been attributed to exogenous processes that take place, but only once the trial stimulus is presented. Such evidence fits comfortably with remarks made by Koch (2003) on the differences in effectiveness of external and internal task cues. In the predictable conditions, the current task was signaled by both an external and an internal cue. The external cue was either the location (in Experiment 1) or the color (in Experiment 2) of the stimulus, but in these cases the cue did not occur until the trial stimulus was presented. The internal cue was the memory for the trial sequence. Any form of advance reconfiguration could therefore be brought about only because of knowledge of the task order. However, it seems that any benefits that might be gained on switch trials, by knowing the task sequence, were actually offset by the demands of trying to retain this information in some form of working memory. The present data provide further support for the idea (Koch, 2003) that advance reconfiguration is not readily entrained by internally generated cues.

A contrasting pattern was found in Experiment 3, because there were significantly smaller switch costs in the 
cued than in the uncued condition. Notably, the effect is at least in part due to facilitated responding on the cued switch trials. This reduction in switch costs in the presence of explicit cuing accords with results reported by Koch (2003). In his experiments, he compared performance in two conditions with alternating runs sequences. In the nocue condition, participants were expected to remember the task order and operate accordingly, because no further task cues were presented. In contrast, in the cue condition, a task precue was presented prior to every trial. Notably, switch costs were considerably smaller in the data for the cue condition than in the no-cue condition when the RSI was $1,000 \mathrm{msec}$. Koch (2003) argued that on the assumption that external cues are more salient than internal cues, external cues "would be more effective in triggering S-R retrieval prior to stimulus onset" (p. 491). A general conclusion, therefore, is that advance reconfiguration is readily brought about by explicit but not by internal task cues.

In addition to the evidence of switch preparation in Experiment 3, it was shown that crosstalk was also smaller in the cued than in the uncued condition. There was no evidence of a selective reduction of crosstalk on cued nonswitch trials such as that found on predictable nonswitch trials in Experiments 1 and 2. One possibility is that the explicit cues gave rise to some form of generic task preparation (Altmann, 2004), in addition to switch preparation. Generic preparation is taken to reflect benefits in stimulusencoding processes that underpin performance on switch and nonswitch trials alike. By this view, the cuing effects reflect facilitation at the level of generating an S-Set representation of the trial stimulus (Karayanidis et al., 2009; Meiran, 2000a, 2000b) in the manner sketched before. In this case, though, dimensional attentional selection operated on both switch and nonswitch trials. This again reflects the effectiveness of explicit cues in bringing about processes of advance reconfiguration. Processes central to the identification of the task-relevant character were primed by the presence of a trial precue.

An additional possibility is that the performance benefits on cued trials also reflect operations concerning the interpretation of the task cue. Under uncued conditions, interpretation of the task cue could begin only once the trial stimulus was presented. In contrast, in the cued conditions, these interpretative processes could begin before the trial stimulus, with the onset of the precue. Hence, the general speeding on cued trials may in part reflect slowing on uncued trials because of the processing overheads concerning task cue interpretation only once the stimulus was presented. The latter ideas fit with those contained in production system models (e.g., Sohn \& Anderson, 2001), in which performance facilitation is due to omitting the retrieval of certain mental operations when the next task is certain.

\section{Congruence Effects}

We have been careful to point out differences between crosstalk and congruence. Crosstalk reflects the difference in performance across bivalent and univalent stimuli. Congruency has been defined in terms of whether or not the two characters in a bivalent stimulus are mapped to the same response (as in the congruent cases) or to different responses (as in the incongruent cases). Across the experiments reported here, crosstalk and congruency effects do dissociate. $^{2}$

The contrasting patterns of crosstalk and congruence effects suggest that these reflect the operation of different mechanisms. It seems that whereas crosstalk reflects task set interference - that is, resolving the conflict as to which task set should be executed - congruency reflects operations located at a later, decisional/response-selection stage of processing. This is reflected in the results where congruent and incongruent responses are equally fast but differ in terms of accuracy. Such a view is not without support (Monsell, Taylor, \& Murphy, 2001; see also Hommel, 1997, for related ideas). According to Monsell et al. (2001), the construct of a task set may be "construed as . . . a filter, a gate or threshold designed to prevent a response tendency associated with a currently irrelevant stimulus attribute from being activated" (p. 148). If, however, such filtering is error prone, then on some trials the irrelevant stimulus attribute will "break through," and the irrelevant response tendency will be activated. Consequently, additional competition will need to be resolved by response selection processes. In this account, stimulus congruency effects are located at the level of response selection but arise in part because of the failure to filter out the irrelevant stimulus attribute. Failures at the level of the filter are assumed to be exacerbated when task set interference is high-for instance, on incongruent switch trials (see also Meiran, 2000a).

There are now several models of task switching that address congruity effects (Altmann \& Gray, 2008; Brown, Reynolds, \& Braver, 2007; Gilbert \& Shallice, 2002; Meiran, 2000a). In these accounts, both effects are typically discussed in terms of the same set of mechanisms. A challenge presented by the present data is that crosstalk and congruity effects do dissociate and therefore reflect the operation of different mechanisms concerning task set activation and, in turn, more central decisional/response processes.

\section{CONCLUSIONS}

The present experiments have provided some further important insights into task-switching performance. It has been shown that when a task was expected to repeat, interference from a competing task set was reduced. Task foreknowledge can therefore be useful, insofar as it facilitates the identification of task-relevant properties of the stimulus. A consequence of this is that task set interference is reduced.

In addition, the present experiments have revealed that under unpredictable conditions, participants attempt to maintain both task sets in some form of working memory. Equivalent levels of crosstalk were found on switch and nonswitch trials, and switch costs tended to be less on unpredictable than on predictable trials.

The data from the final experiment have shown that caution is perhaps warranted in defining task predictabil- 
ity. It has been argued that a truly unpredictable trial is one that cannot be predicted in advance of the trial stimulus. Performance on random trials was compared across cases where trial precues were presented and where they were not. Explicit task precues invoke processes of advance reconfiguration that both speed stimulus identification and reduce costs associated with having to switch tasks. When task predictability is defined relative to a predefined task sequence, the costs of having to remember this sequence and act on it may outweigh the benefits of knowing what the upcoming task is.

\section{AUTHOR NOTE}

We thank Nick Yeung and Erik Altmann for their extremely helpful comments on an earlier version of the manuscript. Correspondence concerning this article should be addressed to either N. Andreadis or P. T. Quinlan, Department of Psychology, University of York, Heslington, York YO10 5DD, England (e-mail: na516@york.ac.uk or ptq1@york.ac.uk).

\section{REFERENCES}

Allport, D. A., Styles, E. A., \& Hsieh, S. (1994). Shifting intentional set: Exploring the dynamic control of tasks. In C. Umiltà \& M. Moscovitch (Eds.), Attention and performance XV: Conscious and nonconscious information processing (pp. 421-452). Cambridge, MA: MIT Press.

Allport, D. A., \& Wylie, G. (1999). Task-switching: Positive and negative priming of task-set. In G. W. Humphreys, J. Duncan, \& A. Treisman (Eds.), Attention, space, and action: Studies in cognitive neuroscience (pp. 273-296). Oxford: Oxford University Press.

Allport, D. A., \& WYlie, G. (2000). Task switching, stimulus-response bindings, and negative priming. In S. Monsell \& J. Driver (Eds.), Control of cognitive processes: Attention and performance XVIII (pp. 3570). Cambridge, MA: MIT Press.

Altmann, E. M. (2004). The preparation effect in task switching: Carryover of SOA. Memory \& Cognition, 32, 153-163.

Altmann, E. M. (2007). Comparing switch costs: Alternating runs and explicit cuing. Journal of Experimental Psychology: Learning, Memory, \& Cognition, 33, 475-483. doi:10.1037/0278-7393.33.3.475

Altmann, E. M., \& GraY, W. D. (2008). An integrated model of cognitive control in task switching. Psychological Review, 115, 602-639. doi:10.1037/0033-295X.115.3.602

Bakeman, R., \& McArthur, D. (1996). Picturing repeated measures: Comments on Loftus, Morrison, and others. Behavior Research Methods, Instruments, \& Computers, 28, 584-589.

Brown, J. W., Reynolds, J. R., \& Braver, T. S. (2007). A computational model of fractionated conflict-control mechanisms in task switching. Cognitive Psychology, 55, 37-85. doi:10.1016/j.cogpsych 2006.09.005

DEJong, R. (2000). An intention-activation account of residual switch costs. In S. Monsell \& J. Driver (Eds.), Control of cognitive processes: Attention and performance XVIII (pp. 357-376). Cambridge, MA: MIT Press.

Eriksen, B. A., \& Eriksen, C. W. (1974). Effects of noise letters upon the identification of a target letter in a nonsearch task. Perception \& Psychophysics, 16, 143-149.

Gilbert, S. J., \& Shallice, T. (2002). Task switching: A PDP model. Cognitive Psychology, 44, 297-337. doi:10.1006/cogp.2001.0770

Gopher, D., Armony, L., \& Greenshran, Y. (2000). Switching tasks and attention policies. Journal of Experimental Psychology: General, 129, 308-339.

GoschKe, T. (2000). Intentional reconfiguration and involuntary persistence in task set switching. In S. Monsell \& J. Driver (Eds.), Control of cognitive processes: Attention and performance XVIII (pp. 331-355). Cambridge, MA: MIT Press.

Hommel, B. (1997). Interactions between stimulus-stimulus congruence and stimulus-response compatibility. Psychological Research, 59, 248-260. doi:10.1007/BF00439302

Karayanidis, F., Mansfield, E. L., Galloway, K. L., Smith, J. L.,
Provost, A., \& Heathcote, A. (2009). Anticipatory reconfiguration elicited by fully and partially informative cues that validly predict a switch in task. Cognitive, Affective, \& Behavioral Neuroscience, 9, 202-215. doi:10.3758/CABN.9.2.202

KePPEL, G., \& Wickens, T. D. (2004). Design and analysis: A researcher's handbook (4th ed.). Upper Saddle River, NJ: Pearson Prentice Hall.

KocH, I. (2003). The role of external cues for endogenous advance reconfiguration in task switching. Psychonomic Bulletin \& Review, 10, 488-492.

Koch, I. (2005). Sequential task predictability in task switching. Psychonomic Bulletin \& Review, 12, 107-112.

Kornblum, S., HasbroucQ, T., \& Osman, A. (1990). Dimensional overlap: Cognitive basis for stimulus-response compatibility-A model and taxonomy. Psychological Review, 97, 253-270.

Meiran, N. (1996). Reconfiguration of processing mode prior to task performance. Journal of Experimental Psychology: Learning, Memory, \& Cognition, 22, 1423-1442.

Meiran, N. (2000a). Modelling cognitive control in task-switching. Psychological Research, 63, 234-249. doi:10.1007/s004269900004

Meiran, N. (2000b). Reconfiguration of stimulus task sets and response task sets during task switching. In S. Monsell \& J. Driver (Eds.), Control of cognitive processes: Attention and performance XVIII (pp. 377399). Cambridge, MA: MIT Press.

Meiran, N. (2005). Task rule-congruency and Simon-like effects in switching between spatial tasks. Quarterly Journal of Experimental Psychology, 58A, 1023-1041. doi:10.1080/02724980443000421

Meiran, N., Chorev, Z., \& SaPIR, A. (2000). Component processes in task switching. Cognitive Psychology, 41, 211-253. doi:10.1006/ cogp. 2000.0736

Monsell, S. (2003). Task switching. Trends in Cognitive Sciences, 7 , 134-140. doi:10.1016/S1364-6613(03)00028-7

Monsell, S., Sumner, P., \& Waters, H. (2003). Task-set reconfiguration with predictable and unpredictable task switches. Memory \& Cognition, 31, 327-342.

Monsell, S., TAYlor, T. J., \& MurPhy, K. (2001). Naming the color of a word: Is it responses or task sets that compete? Memory \& Cognition, 29, 137-151.

Monsell, S., Yeung, N., \& Azuma, R. (2000). Reconfiguration of task-set: Is it easier to switch to the weaker task? Psychological Research, 63, 250-264. doi:10.1007/s004269900005

PASHLER, H. E. (2000). Task switching and multitask performance. In S. Monsell \& J. Driver (Eds.), Control of cognitive processes: Attention and performance XVIII (pp. 277-307). Cambridge, MA: MIT Press

Quinlan, P. T., \& Dyson, B. J. (2008). Cognitive psychology. Harlow, U.K.: Pearson.

Rogers, R. D., \& Monsell, S. (1995). Costs of a predictable switch between simple cognitive tasks. Journal of Experimental Psychology: General, 124, 207-301.

Schneider, W., Eschman, A., \& Zuccolotto, A. (2002). E-Prime user's guide. Pittsburgh, PA: Psychology Software Tools.

Simon, J. R. (1990). The effects of an irrelevant directional cue on human information processing. In R. W. Proctor \& T. G. Reeves (Eds.), Stimulus-response compatibility (pp. 31-86). Amsterdam: Elsevier.

SoHN, M.-H., \& ANDERson, J. R. (2001). Task preparation and task repetition: Two-component model of task switching. Journal of Experimental Psychology: General, 130, 764-778.

SoHN, M.-H., \& CARLSON, R. A. (2000). Effects of repetition and foreknowledge in task-set reconfiguration. Journal of Experimental Psychology: Learning, Memory, \& Cognition, 26, 1445-1460.

Tornay, F. J., \& Milán, E. G. (2001). A more complete task-set reconfiguration in random than in predictable task switch. Quarterly Journal of Experimental Psychology, 54A, 785-803.

Zhang, H., Zhang, J., \& Kornblum, S. (1999). A parallel distributed processing model of stimulus-stimulus and stimulus-response compatibility. Cognitive Psychology, 38, 386-432. doi:10.1006/ cogp. 1998.0703

\section{NOTES}

1. We have explored possible effects of RSI in a different series of experiments in which participants had to classify a single digit as being 
either high/low (i.e., greater than 5/less than 5) or odd/even (see Koch, 2003, 2005; Monsell et al., 2003). In one experiment, a repeated measures design was used, and the RSIs - tested in separate blocks of trials - were 250 and $1,200 \mathrm{msec}$, respectively. We found that the switch costs did reduce with increases in RSI and that the reduction was more marked on unpredictable than on predictable trials. This difference is in line with that reported by Tornay and Milán (2001), but switch costs were still present at the longer RSI. Clearly, there is something special about testing manipulations of RSI with repeated measures designs (cf. Altmann, 2004).

2. During review, it was pointed out that, in fact, the distinction between the two effects might be blurred in our experiments because there is more than one form of congruency that is inherent to our stimuli. There is a large literature on the Simon effect, whereby responses are better facilitated when the position of the imperative stimulus is, in some sense, compatible with the response than when it is incompatible with the response (see Simon, 1990, for a review).

In our experiments, the task-relevant character occurred on the right or the left of the character pair, and keypress responses were also lateral- ized. Therefore, the stimuli could be classified as congruent or incongruent according to the compatibility of the task-relevant character and the response. We do not deny that such S-R compatibility effects may be present in our data. Indeed, such effects can play an important role in task switching (see Meiran, 2005). However, a proper consideration of these effects would take us in a direction away from the present focus of attention. Although the reported effects of congruency may themselves conceal effects of S-R compatibility, the stimuli were balanced such that equivalent compatible and incompatible cases were tested across the defined congruent, incongruent, and neutral trials. This kind of S-R compatibility cannot account for the crosstalk effects we describe. For a much more thorough exploration of related issues, see Kornblum, Hasbroucq, and Osman (1990) and Zhang, Zhang, and Kornblum (1999).

(Manuscript received May 11, 2009;

revision accepted for publication April 19, 2010.) 